\title{
EVIDENCIANDO PROCESSOS METACOGNITIVOS EM ADA/AVA
}

Simone Hack da Silva Koch - Universidade Feevale - simonehsk@feevale.br

Liliana M. Passerino - UFRGS - liliana@ cinted.ufrgs.br

\section{RESUMO}

Quando se propõe situações de aprendizagem, o professor fica surpreso em constatar que os alunos desenvolvem uma série de condutas. Algumas não muito lógicas, revelam-se eficazes, e outras, aparentemente mais adequadas, dão resultados desconcertantes. Como compreender o que o aluno faz ou quis fazer? Como perceber suas verdadeiras aprendizagens? Nesse contexto, este trabalho teve como foco principal a investigação sobre como promover e evidenciar, por meio de estratégias de ensino e aprendizagem mediadas pelas TIC, processos metacognitivos nos sujeitos em ADA/AVA numa perspectiva sócio-histórica. Estruturou-se num estudo de caso (multicasos) de alunos de ensino fundamental. Os resultados mostram que as estratégias de ensino e aprendizagem, através de ações mediadas em ambientes ADA/AVA, evidenciam e promovem processos metacognitivos.

Palavras-chave: aprendizagem, metacognição, ADA/AVA, auto-regulação, mediação.

\begin{abstract}
When one proposes learning situations, the teacher is surprised to find that students develop a series of pipes. Some not very logical, they often prove effective, and other, seemingly more appropriate, give confusing results. How to understand what students do or wanted to do? How to realize their true learning? Therefore, this study was to focus research on how to promote and demonstrate, through strategies of teaching and learning mediated by ICT, metacognitive processes in the subjects in ADA / AVA in a socio-historical. Structured on a case study (multicases) of primary school students. The results show that strategies of teaching and learning through actions mediated environments ADA / AVA, demonstrate and promote metacognition.
\end{abstract}

Keywords: learning, metacognition, ADA/AVA, self-regulation, mediation.

\section{Introdução}

O crescente desenvolvimento das tecnologias de informação e comunicação (TIC) se tornou um agente relevante de aprendizagem. A disseminação das ferramentas tecnológicas estruturadas em ambientes digitais/virtuais (ADA/AVA) ${ }^{1}$ ou de aprendizagem, vem se tornando um dos pontos principais da comunicação e da aprendizagem entre alunos e professores. Tais ferramentas vêm sendo utilizadas na mediação de processos cognitivos, de forma a organizar e acompanhar a construção dos saberes dos alunos com muito mais frequência (Santarosa et al. 2010). Nessa

\footnotetext{
1 Ambientes digitais/virtuais de aprendizagem (ADA/AVA) envolvem o uso de softwares e sistemas de âmbito educativo modelados sob concepções de desenvolvimento e aprendizagem. Privilegiam paradigmas educacionais com diferentes referenciais teóricos. (Santarosa et al, 2010) Neste estudo assume-se o enfoque construtivista/interacionista que enfatiza o processo interativo no qual o aluno é agente ativo do processo de construção do conhecimento.
} 
perspectiva a tecnologia pode amplificar práticas já existentes, bem como a maneira como as pessoas aprendem, colaboram, partilham e progridem através de seu uso, pois "diversas mudanças importantes nas relações sociais podem advir da interação humana que cerca o processo tecnológico, e não somente da operação dos computadores ou do uso da Internet." (Warschauer, 2006 p. 284).

Estudos $^{2}$ apontam que perceber a própria aprendizagem, auto-regulá-la, num processo mediado, através de estratégias de ensino e aprendizagem, indica evidências de processos metacognitivos, ou seja, um processo internalizado e auto-regulado. $\mathrm{O}$ objetivo deste artigo, portanto, é apresentar alguns resultados de uma pesquisa que investigou como promover e evidenciar, por meio de estratégias de ensino e aprendizagem mediadas pelas TIC, processos metacognitivos de sujeitos que participam de ADA/AVA, (Koch, S. H. S., 2011).

\section{Aprendizagem, Mediação e Metacognição}

De acordo com Vygotsky (1998), a aprendizagem tem início muito antes da aprendizagem escolar. Para ele, a aprendizagem escolar nunca parte do zero, pois toda a aprendizagem tem uma pré-história. Por exemplo, a criança antes mesmo de estudar matemática, já teve contato com quantidades, com várias operações de adição, subtração, divisão, complexas e simples. Portanto, não se pode ignorar o conhecimento prévio e nem pensar que a aprendizagem escolar começa no vácuo, mas sim que é precedida sempre por um processo de desenvolvimento, alcançado antes de entrar em contato com a educação formal pela aprendizagem da criança no seu contexto, sendo que esta continua tanto na escola como fora dela.

$\mathrm{Na}$ teoria sócio-histórica a boa aprendizagem tem impacto no desenvolvimento dos processos cognitivos (ou processos psicológicos superiores), de maneira que a "o processo de desenvolvimento não coincide com o da aprendizagem, o processo de desenvolvimento segue o da aprendizagem, que cria a área de desenvolvimento proximal" (Vygotsky 1998 p.103).

Ao considerar o aprendizado um aspecto essencial na criação da zona de desenvolvimento proximal, o autor propõe que o aprendizado desperta vários processos internos de desenvolvimento, que são capazes de operar somente quando a criança interage com pessoas em seu ambiente e quando em operação com seus companheiros.. Uma vez internalizados esses processos, eles tornam-se parte das aquisições do desenvolvimento independente.

A ZDP pode oferecer tanto a psicólogos quanto aos educadores um mecanismo através do qual pode ser compreendido o curso interno do desenvolvimento, e que o uso desse método pode permitir a tomada em consideração dos ciclos e processos de maturação que já estão completos, além dos que estão em estado de formação (Fino, 2001). pois "a ZDP permite delinear o futuro imediato da criança e o seu estado dinâmico de desenvolvimento" (Vygotsky, 1998 apud Fino, 2001).

Fino (2001), aponta três implicações sobre a ZDP: a primeira como "uma janela de aprendizagem"; a segunda, "o tutor como um agente metacognitivo" e a terceira, "a importância dos pares como mediadores da aprendizagem".

A segunda implicação, estreitamente relacionada ao foco dessa pesquisa, aponta o tutor como agente metacognitivo. Ao monitorizar e dirigir a atividade do

2 Para autores como Flavell (1985), Mateos (2001), Sanjurjo (2002), Brown, Campione e Day (1981,1987), Dewey (1989), Lopes e Sá (1993), Garner (1989), Couceiro (2003), Wertsch (1999), Vygotsky (1996,1998,2001), Moraes e Valente (1991) e Valente $\left(1989,1989^{\mathrm{a}}, 1989 \mathrm{~b}\right)$ 
aluno, em direção à conclusão da tarefa ou resolução do problema, o professor trabalha como regulador do processo e analista do conhecimento. "Quando o aprendiz interioriza o comportamento cognitivo, o professor transfere para ele a responsabilidade e o controle metacognitivo" (Fino, 2001, p.12). Nesse processo o aprendiz é capaz de tomar consciência sobre o próprio conhecimento, como também sobre os valores interiorizados que lhes estão associados. O professor pode ser o guia e confrontar o aprendiz com as tarefas de reconhecimento da sua aprendizagem.

E por fim, a terceira implicação: a importância dos pares como mediadores da aprendizagem”. Fino (2001) aponta que, na perspectiva de Vygotsky (1978,) a autoregulação é precedida de uma regulação exterior. Essa regulação exterior acontece num contexto social, no qual um adulto ou uma criança mais capaz guia a atividade do outro menos capaz. Na medida em que o menos capaz vai desenvolvendo seus conhecimentos e habilidades, o mais capaz vai lhe entregando o controle das operações. Então, enquanto o aprendiz vai assumindo maior responsabilidade cognitiva vai gradualmente interiorizando os procedimentos e o conhecimento envolvido. Desse modo a regulação exterior se transforma em auto-regulação (King, 1977 apud Fino, 2001). Nesse processo de mediação da aprendizagem por pares mais capazes, se tem um dos arranjos de ensino e de aprendizagem, que também é considerado um meio "natural" de aprendizagem.

Importante ressaltar que na concepção sócio-histórica, a mediação envolve toda a atividade humana, que só pode ser entendida se considerarmos os instrumentos e $\operatorname{signos}^{3}$ que mediam a mesma. É através de tais instrumentos e signos que o processo de mediação ocorre e pode desencadear o desenvolvimento dos processos psicológicos superiores (PPS).

Note-se, que a mediação não é concebida como fator que facilita a atividade, mas, que a configura e a define, ou seja, sem ela a atividade seria qualitativamente diferente (Wertsch, 1993). No desenvolvimento dos processos psicológicos superiores (PPS), os signos são internalizados de forma tal que os PPS “incorporam à sua estrutura, como parte central de todo o processo, o emprego de signos como meio fundamental de orientação e domínio nos processos psíquicos" (Vygotsky, 2001, p.161). A mediação, assim vista, é um processo dinâmico, no qual intervém ferramentas e signos numa ação ${ }^{4}$ que tem a capacidade de modelar a ação, mas não a determina. Pois, "[...] a mais sofisticada análise dessas ferramentas não pode, por si só, nos dizer como elas são aceitas e usadas por indivíduos para conduzir a ação" (Wertsch, 1998, p.29).

Alguns pesquisadores apontam a existência de mecanismos que poderiam identificar um signo internalizado e, portanto acompanhar o desenvolvimento cognitivo do sujeito (Diaz et al., 1993), (Gallimore; Tharp, 1993), (Wertsch, 1999). Uma das possibilidades para analisar o processo de internalização, foi o proposto por Passerino (2005) que sugere dividir o processo de internalização em três sub-processos: controle, autocontrole e auto-regulação. Sendo que a internalização propriamente dita acontece entre os estágios de autocontrole e auto-regulação.

Nas Categorias de Controle o sujeito mais experiente é responsável pela ação e delimita o processo inicial de apropriação através de um controle direto ou indireto. $\mathrm{Na}$ categoria Autocontrole o sujeito ainda apresenta ações esperadas, obedecendo a um tutor internalizado. Na categoria Auto-regulação, que, de acordo com a autora

\footnotetext{
3 Os instrumentos e signos são entendidos como os efeitos físicos de mudanças no mundo e efeitos psicológicos sobre o próprio homem, resultantes da sua própria ação. (VYGOSKY, 1998).

4Para Wertsch (1998) a ação humana pode ser tanto interna quanto externa, individual ou em grupo, mas toda ação tem sempre uma dimensão psicológica e sócio-cultural.
} 
Passerino (2005), se diferencia da categoria do Autocontrole, não pela internalização das ordens e diretivas do tutor, mas na capacidade emergente de planejar e definir objetivos próprios organizando funcionalmente sua conduta para os mesmos e adaptando-a de acordo com o contexto. É na categoria auto-regulação, que esse estudo esteve focado, com a intenção de entender a sua relação com o processo metacognitivo (Figura 1).

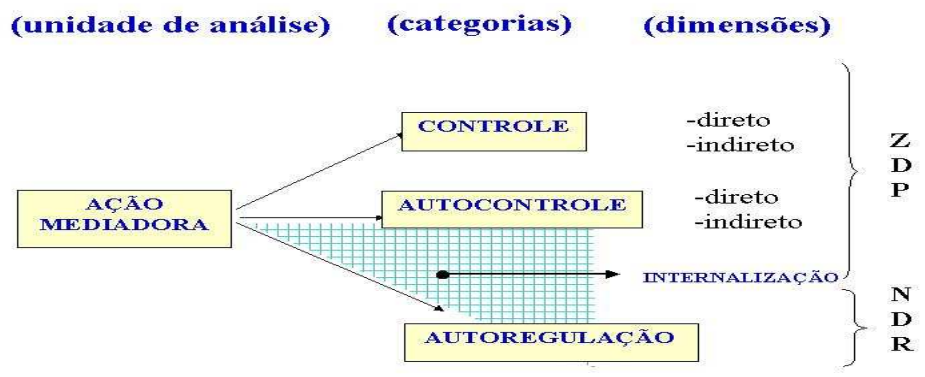

Figura 1 - Categorias Iniciais da Ação Mediadora e suas dimensões. (Passerino, 2005)

Na busca dessa relação, vale citar Wertsch (1999) e seus estudos sobre a ação humana e ação mediada. Wertsch (1999) cita Burke (1969) ao definir que: "só se pode entender a ação humana adequadamente invocando perspectivas múltiplas e examinando as tensões dialéticas que existem entre elas" (Burke, 1969 p.84). Para tal Wertsch (1999) determina que seja necessário usar cinco princípios que permitem determinar $m$ a ação humana: o ato, a cena, o agente, a agência e o propósito. Designa as questões: "o que fez?" (ato), "quando e onde fez?" (cena), "quem fez?" (agente), "como fez?" (agencia) e "por que fez?" (propósito) para constituir como ferramenta na realização de investigações sobre a ação e os motivos humanos e não apenas para representar a realidade, mas sim para interpretar e analisar de uma forma dialética a ação humana, defende Burke (1969).

$\mathrm{Na}$ escola, um dos instrumentos mediadores mais importantes encontra-se nos signos lingüísticos, isto é, a linguagem é mediadora do saber, pois tem papel crucial na transformação da aprendizagem, já que é através dela que o professor poderá situar a ZPD, ou zona de construção de conhecimento dos alunos, permitindo com que haja construção de conhecimento e conseqüentemente avanço na aprendizagem.

Pode-se então dizer que a mediação social das atividades, de acordo com as estratégias de ensino e de aprendizagem utilizadas, permite a construção partilhada de instrumentos e de processos de significação que irão mediar as operações abstratas do pensamento, dando origem ao processo de internalização, assim como o processo metacognitivo.

Finalmente, destaca-se que a mediação através das ferramentas ADA/AVA pode ser vista como processo social no qual os sujeitos constroem seus conhecimentos e se constituem como indivíduos numa inter-relação constante entre o inter e o intrapessoal, a ponto de perceber seu próprio processo de aprendizagem e auto-regulá-lo (Passerino, 2005).

\section{A Auto-regulação, metacognição e o contexto educativo}

Vygotsky (1998) postula a relação direta entre a consciência dos próprios processos cognitivos e a capacidade para controlá-los. Contudo, considera que, inicialmente, o controle interno não é, necessariamente, consciente, nem objeto de reflexão. Por isso a ação mediadora se torna muito importante nesse processo. Na 
perspectiva sócio-histórica a consciência é sempre consciência socialmente mediada de alguma coisa (Vygotsky, 1928-1933/1996): é a própria relação da criança com o meio, e, de modo mais tardio, da pessoa consigo própria (Luria, 1988). A consciência não é sistema estático, mecanicista: relaciona-se ao desenvolvimento da conduta voluntária. (Toassa, 2006).

De acordo com os estudos de Couceiro (2007), a auto-regulação envolve três grandes componentes. $\mathrm{O}$ primeiro, o processamento, que se refere às estratégias cognitivas que o sujeito utiliza para processar o material de aprendizagem para alcançar seus objetivos. O segundo, a regulação, que inclui as estratégias metacognitivas (utilizadas para organizar, coordenar, regular e testar as próprias atividades de processamento e exercer o controle sobre a própria aprendizagem), que estão relacionadas com as atividades de processamento. E o terceiro componente, as experiências metacognitivas (positivas ou negativas), que ocorrem no decurso da atividade cognitiva e que proporcionam o feedback interno consciente acerca do progresso, passado ou futuro, com vista a alcançar o objetivo (Bouchard-Bouffard et al., 1993).

Sanjurjo (2002), baseada em seus estudos sobre processos metacognitivos como um modo específico de reflexão ${ }^{5}$ com aporte de Schön, defende que esse processo não é linear, mas sim espiralado, as etapas se modificam e retornam continuamente em ambas as direções. A relação que estabelece com o processo reflexivo, não uma reflexão filosófica sobre o conhecimento, mas uma tomada de consciência do próprio sujeito sobre suas estratégias e processos cognitivos. No entanto, concordamos com Vygotsky (1996) e Brown (1981) que consideram que o desenvolvimento do controle cognitivo e metacognitivo é, primeiramente, um processo social. Um processo social onde a mediação social das atividades, de acordo com as estratégias de ensino e de aprendizagem utilizadas, permite a construção partilhada de instrumentos e de processos de significação que irão mediar as operações abstratas do pensamento, dando origem ao processo de internalização, assim como o processo metacognitivo. Ou seja, é na participação de interações triádicas em cenas de atenção conjunta que a compreensão dos co-específicos como seres intencionais iguais a si próprio, num processo cultural, caracterizará a competência cognitiva (Tomazello, 2003). Essa competência cognitiva passa, primeiramente, pela compreensão dos objetos, pela compreensão do outro e por fim a compreensão de si mesmo, num processo que culminaria na auto-regulação e que promove a metacognição.

\section{O estudo:}

O estudo foi realizado com um grupo de alunos participantes de um programa social da cidade de Novo Hamburgo, região metropolitana de Porto Alegre- RS. O grupo era formado por nove alunos interessados em desenvolver um filme. Cada um dos alunos do grupo assumiu um papel definido, desde direção até editoração do filme. Concomitante a esse processo, o grupo estabelecia trocas com um grupo de alunos na Turquia que tinha o mesmo objetivo. O nome desse projeto de aprendizagem se deu Janelas para o Mundo, pois através das janelas do computador, MSN, SKYPE e BLOG, foram realizadas as trocas entre os grupos. Além dessas ferramentas, os alunos utilizaram recursos tecnológicos como Word, Pivot, Movie Maker, Cmap Tools, máquina fotográfica e filmadora, configurando o ambiente digital de

5Sanjurjo aponta que a metacognição não é somente reflexão. Mas um tipo específico de reflexão; aquela que centraliza a atenção nos próprios processos de cognição. 
aprendizagem(ADA). Como ambiente virtual de aprendizagem (AVA) utilizaram o MOODLE através de ferramentas fórum, diário e envio de arquivos. Nesse ambiente eram discutidos o que os alunos pensavam sobre as atividades desenvolvidas através de diferentes tipos de estratégias de ensino e aprendizagem. Todo esse processo envolveu 30 encontros de 3horas.

A metodologia adotada foi o estudo de três casos, três dos alunos participantes do grupo, com finalidade exploratória. Explanatória, por analisar as evidências de processos metacognitivos nos registros durante o curso real dos acontecimentos com diferentes estratégias de ensino e aprendizagem nos ADA/AVA.

A principal técnica de pesquisa foi a observação participante, durante os 30 encontros. Entrevistas, questionários, análise de documentos e o método Think Aloud ${ }^{6}$ ou método "Pensar em Voz Alta" também foram utilizados como técnicas secundárias de pesquisa. Para a coleta dos dados foram utilizados: registros em vídeo, registros nas ferramentas da plataforma Moodle, registros nos arquivos gerados pelos alunos a partir das estratégias de ensino e registros no diário de campo da pesquisadora.

A pesquisa foi realizada em 4 etapas. Sendo elas: $1^{a}$ etapa - Configuração do ambiente, da proposta e do grupo de pesquisa; $2^{\mathrm{a}}$ etapa - intervenção e coleta dos dados; $3^{\mathrm{a}}$ etapa- seleção dos casos para a pesquisa e $4^{\mathrm{a}}$ etapa - análise dos dados coletados.

As unidades e categorias de análise criadas foram embasadas nos referencias de apresentados anteriormente, sendo elas (Quadro 1):

\begin{tabular}{|c|c|}
\hline Unidade de análise & Categorias de análise \\
\hline \multirow{2}{*}{ Estratégias de ensino e aprendizagem } & $\begin{array}{l}\text { Tipo de estratégia de ensino e aprendizagem: projeto } \\
\text { de aprendizagem, tempestade cerebral, soluções de } \\
\text { problemas e construção de mapas conceituais. }\end{array}$ \\
\hline & $\begin{array}{l}\text { Princípios da ação humana: serão analisados: o ato: O } \\
\text { que fez? a cena Quando e onde fez? o agente Quem } \\
\text { fez? agência Como fez? propósito por que fez? }\end{array}$ \\
\hline \multirow{2}{*}{$\begin{array}{c}\text { Manifestações metacognitivas nas ferramentas } \\
\text { ADA/AVA }\end{array}$} & Posição do agente: mediador e aluno \\
\hline & $\begin{array}{l}\text { Mediação: categorias de Controle (direto ou indireto), } \\
\text { Autocontrole (direto ou indireto) e Auto- regulação }\end{array}$ \\
\hline
\end{tabular}

Quadro 1: Unidades e categorias de análise

\section{Resultados}

Para análise dos dados foram construídos quadros com os princípios da ação humana, posição do agente e ação mediadora para cada uma das estratégias de ensino e aprendizagem de cada um dos casos analisados. Para a análise das manifestações cognitivas foram destacados os indícios quanto a posição do agente e a ação mediadora.

Para cada uma das estratégias utilizadas foram criados quadros sínteses (quadros 2, 3, 4 e 5), demonstrando e relacionando as evidências de controle (C), autocontrole (AC) e Autorregulação (AR). Nos quadros a indicação $\mathbf{X}$ representa a evidência no ambiente digital de aprendizagem (ADA) e $\mathbf{0}$ no ambiente virtual de aprendizagem(AVA).

\begin{tabular}{|c|c|c|c|c|c|c|c|c|c|c|}
\hline & \multicolumn{3}{|l|}{$3^{\circ}$ encontro } & \multicolumn{3}{|c|}{$4^{\circ}$ encontro } & \multicolumn{3}{|c|}{$5^{\circ}$ encontro } & \multirow{2}{*}{$\frac{11^{\circ} \text { encont }}{\mathrm{A}}$} \\
\hline & A & AC & $\mathbf{A R}$ & A & AC & $\mathbf{A R}$ & A & AC & $\mathbf{A R}$ & \\
\hline $\mathrm{CC} 1$ & $\mathrm{x}$ & $\mathrm{xX}$ & & $\mathrm{xxx}$ & $\mathrm{xX}$ & $\mathrm{xx}$ & & & $\mathrm{x}$ & \\
\hline $\mathrm{CC} 2$ & $\mathrm{x}$ & & & XXx & XXx & $x x$ & & $\mathrm{x}$ & & \\
\hline
\end{tabular}

6 O método Think Aloud tem suas raízes na pesquisa psicológica. Ele foi desenvolvido a partir do método mais introspecção. O método de introspecção é baseado na ideia de que pode-se observar os eventos que ocorrem na consciência, mais ou menos como se pode observar eventos no mundo exterior. (SOMEREN, BARNARD E SANDBERG, 1994) 
Quadro 2: Tabela síntese estratégia Tempestade Cerebral

\begin{tabular}{|c|c|c|c|c|c|c|c|c|c|c|c|c|c|c|c|c|c|c|c|c|c|c|c|c|c|c|c|}
\hline & \multicolumn{3}{|c|}{$\begin{array}{c}7^{\circ} \\
\text { encontro }\end{array}$} & \multicolumn{3}{|c|}{$\begin{array}{c}8^{\circ} \\
\text { encontro }\end{array}$} & \multicolumn{3}{|c|}{$\begin{array}{l}9^{\circ} \\
\text { Encontro }\end{array}$} & \multicolumn{3}{|c|}{$\begin{array}{c}10^{\circ} \\
\text { encontro }\end{array}$} & \multicolumn{3}{|c|}{$\begin{array}{c}15^{\circ} \\
\text { encontro }\end{array}$} & \multicolumn{3}{|c|}{$\begin{array}{c}17^{\circ} \\
\text { encontro }\end{array}$} & \multicolumn{3}{|c|}{$\begin{array}{c}20^{\circ} \\
\text { encontro }\end{array}$} & \multicolumn{3}{|c|}{$\begin{array}{c}22^{\circ} \\
\text { encontro }\end{array}$} & \multicolumn{3}{|c|}{$\begin{array}{c}23^{\circ} \\
\text { encontro }\end{array}$} \\
\hline & C & $\begin{array}{l} \\
\text { C } \\
\end{array}$ & $\begin{array}{l}\mathbf{A} \\
\mathbf{R} \\
\end{array}$ & $\bar{C}$ & $\begin{array}{l}\mathrm{A} \\
\mathrm{C}\end{array}$ & $\begin{array}{l}\mathbf{A} \\
\mathbf{R} \\
\end{array}$ & $\overline{\mathbf{C}}$ & $\begin{array}{l}\mathbf{A} \\
\mathrm{C} \\
\end{array}$ & $\begin{array}{l}\mathbf{A} \\
\mathbf{R} \\
\end{array}$ & $\bar{C}$ & $\begin{array}{l}\mathbf{A} \\
\mathbf{C} \\
\end{array}$ & $\begin{array}{l}\mathbf{A} \\
\mathbf{R} \\
\end{array}$ & $\bar{C}$ & $\begin{array}{l}\mathrm{A} \\
\mathrm{C}\end{array}$ & $\begin{array}{l}\mathbf{A} \\
\mathbf{R} \\
\end{array}$ & $\bar{C}$ & \begin{tabular}{l|l|}
$\mathbf{A}$ \\
$\mathrm{C}$ \\
\end{tabular} & $\begin{array}{l}\mathbf{A} \\
\mathbf{R} \\
\end{array}$ & $\begin{array}{ll}\mathrm{C} \\
\end{array}$ & $\begin{array}{l}\mathrm{A} \\
\mathrm{C}\end{array}$ & \begin{tabular}{|l|}
$\mathbf{A}$ \\
$\mathbf{R}$ \\
\end{tabular} & $\begin{array}{ll}\mathrm{C} \\
\end{array}$ & \begin{tabular}{l|l}
$\mathbf{A}$ \\
$\mathrm{C}$ \\
\end{tabular} & $\begin{array}{l}\mathbf{A} \\
\mathbf{R} \\
\end{array}$ & $\bar{C}$ & $\begin{array}{l}\mathrm{A} \\
\mathrm{C} \\
\end{array}$ & $\begin{array}{l}\mathbf{A} \\
\mathbf{R}\end{array}$ \\
\hline $\mathrm{C} 1$ & & & 0 & & & $x$ & & $x$ & $x$ & & & & & & & 0 & & & & & 0 & & & 0 & 0 & 0 & 0 \\
\hline $\mathrm{C} 2^{2}$ & & & 0 & & & $x$ & & $x$ & $x$ & & & & & & 0 & & & 0 & & 0 & & & 0 & & & 0 & \\
\hline C3 & & & 0 & & & $x$ & & $\begin{array}{l}X \\
X\end{array}$ & & & $x$ & & & & & & & 0 & & 0 & & 0 & & & & $\begin{array}{l}0 \\
0\end{array}$ & 0 \\
\hline
\end{tabular}

Quadro 3: Tabela síntese estratégia Portfólio

\begin{tabular}{|c|c|c|c|}
\hline & \multicolumn{3}{|c|}{$24^{\circ}$ encontro } \\
\hline & C & AC & AR \\
\hline C1 & & $\mathrm{X}$ & \\
\hline $\mathrm{C} 2$ & & $\mathrm{X}$ & \\
\hline $\mathrm{C} 3$ & $\mathrm{X}$ & & \\
\hline
\end{tabular}

Quadro 4: Tabela síntese estratégia Mapa Conceitual

\begin{tabular}{|c|c|c|c|c|c|c|c|c|c|c|c|c|}
\hline & \multicolumn{3}{|c|}{$19^{\circ}$ encontro } & \multicolumn{3}{|c|}{$24^{\circ}$ encontro } & \multicolumn{3}{|c|}{$26^{\circ}$ encontro } & \multicolumn{3}{|c|}{$27^{\circ}$ encontro } \\
\hline & $\mathbf{C}$ & $\mathbf{A C}$ & $\mathbf{A R}$ & $\mathbf{C}$ & $\mathbf{A C}$ & $\mathbf{A R}$ & $\mathbf{C}$ & $\mathbf{A C}$ & $\mathbf{A R}$ & $\mathbf{C}$ & $\mathbf{A C}$ & $\mathbf{A R}$ \\
\hline $\mathrm{C} 1$ & & $\mathrm{X}$ & & $\mathrm{X}$ & $\mathrm{XXXXX}$ & $\mathrm{X}$ & 0 & & 00 & 0 & & 00 \\
\hline $\mathrm{C} 2$ & & & & $\mathrm{X}$ & $\mathrm{XXXX}$ & $\mathrm{X} 0$ & 00 & & 0000 & 00 & 0 & 000 \\
\hline $\mathrm{C} 3$ & & & & & $\mathrm{X} 0$ & $\mathrm{XX}$ & 0 & 000 & 0000 & & 0 & 0 \\
\hline
\end{tabular}

Quadro 5: Tabela síntese estratégia Solução de Problemas

Após uma minuciosa análise em relação a cada uma das evidências apresentas nas diferentes estratégias de ensino e aprendizagem, foi possível criar o quadro 6 que relaciona os casos estudados, as estratégias utilizadas, ambientes e a ação mediadora: Legenda:

\begin{tabular}{|c|c|c|c|c|c|}
\hline ADA & AVA & $\begin{array}{c}\text { Estratégia Tempestade } \\
\text { Cerebral }\end{array}$ & $\begin{array}{c}\text { Estratégia } \\
\text { Portfólio }\end{array}$ & $\begin{array}{c}\text { Estratégia Solução de } \\
\text { Problemas }\end{array}$ & $\begin{array}{c}\text { Estratégia Mapa } \\
\text { Conceitual }\end{array}$ \\
\hline $\mathbf{X}$ & $\mathbf{0}$ & TC & $\mathbf{P}$ & SP & MC \\
\hline
\end{tabular}

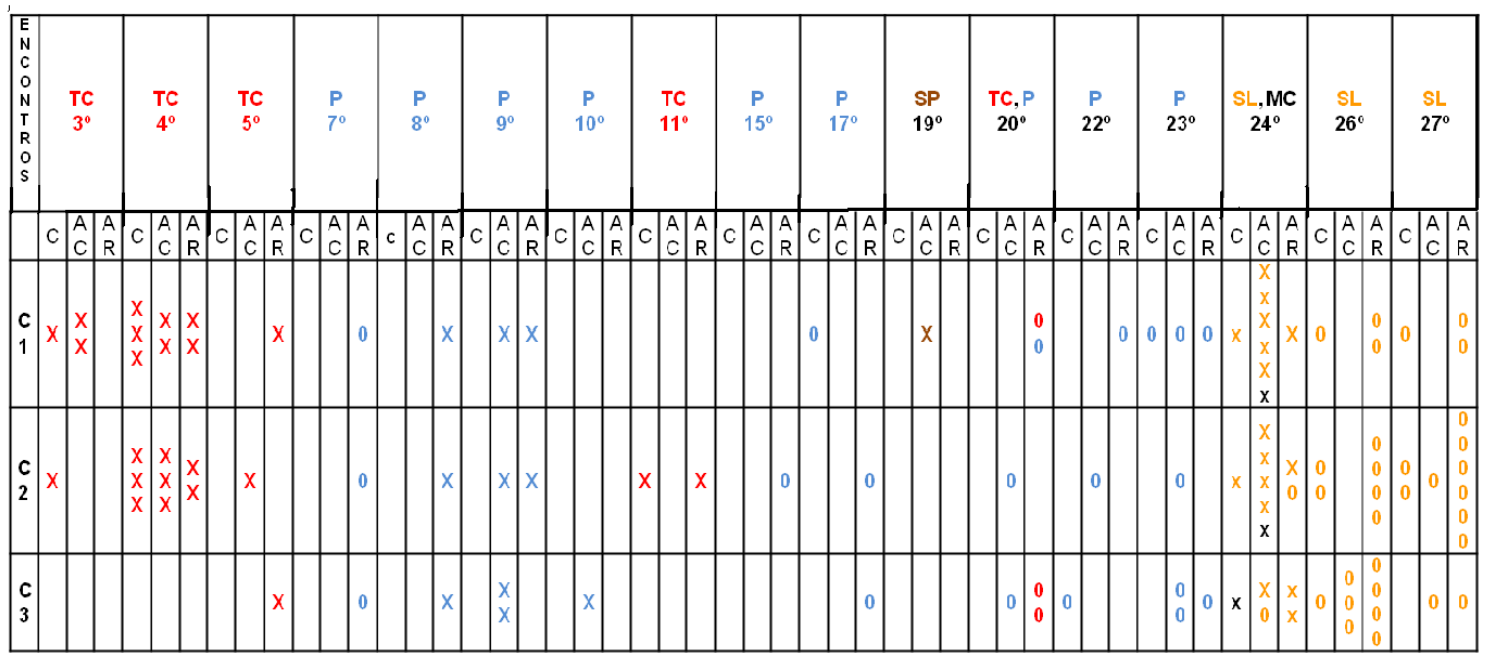

Quadro 6: Análise do processo metacognitivo 
O quadro 6 mostra que na medida em que os alunos foram se familiarizando com o contexto (ADA/AVA) maior o número de indícios de metacognição por parte de todos os casos. Percebe-se que há maior concentração da categoria auto-regulação no final do projeto no AVA enquanto que no início era mais presente no ADA. Esse movimento pode ser devido à estratégia e ferramenta AVA utilizada, devido à familiarização com o ambiente, bem como devido à presença dos pares durante todo o processo.

Podemos observar que num determinado período ( $10^{\circ}$ ao $19^{\circ}$ encontro) menos evidências de mediação foram registradas, tanto no ambiente digital quanto no ambiente virtual de aprendizagem. De acordo com Sanjurjo (2002), o processo metacognitivo passa por diferentes momentos: leitura crítica da realidade, realização das ações e reflexão, num movimento não linear e continuo. No período mencionado $\left(10^{\mathrm{a}}\right.$ ao $19^{\circ}$ encontros) a falta de evidências nos registros ADA/AVA demonstra o momento da realização das ações em que os casos estavam envolvidos. A partir do $20^{\circ}$ encontro os casos demonstraram envolver-se com as reflexões, deixando os registros nas ferramentas disponibilizadas em ambos ambientes, através estratégias de ensino e aprendizagem utilizadas.

Importante ressaltar aqui que todo esse processo não é linear, porém os registros analisados demonstram que os casos planificavam suas ações para realizá-las. Como estavam envolvidos em cenas de atenção conjunta, o período de execução das ações acontece quase que concomitantemente com os três casos no período citado.

Ao apresentar a estratégia Solução de Problemas foi pedido aos alunos explicações de como solucionariam os desafios apresentados, esse pedido de explicação se transformou em momentos de reflexão, que pode ser evidenciado através das ferramentas AVA. Podemos observar que as ferramentas virtuais e as estratégias Tempestade Virtual e Solução de Problemas contribuíram para desencadear o processo metacognitivo. O tempo e o tipo de trabalho proposto permitiram ao grupo criar autonomia e confiança, o qual passou a se expressar com mais facilidade através das ferramentas aprendidas ao longo dos encontros.

Podemos dizer que as ações mediadas, de acordo com as estratégias de ensino e de aprendizagem, permitiram a construção partilhada de instrumentos e de processos de significação para mediar as operações abstratas do pensamento, dando origem ao processo de internalização, assim como o processo metacognitivo.

Cabe aqui destacar (Tomasello, 2003) quando diz que é na participação de interações triádicas em cenas de atenção conjunta que a compreensão dos co-específicos como seres intencionais iguais a si próprio, num processo cultural, caracterizará a competência cognitiva. Essa competência cognitiva passa, primeiramente, pela compreensão dos objetos, pela compreensão do outro e por fim a compreensão de si mesmo, num processo que culminaria na auto-regulação e que promove a metacognição.

\section{Considerações Finais}

Concluindo, os dados mostraram que através das estratégias de ensino e aprendizagem, como Tempestade Cerebral, Solução de Problemas, Portfólio e Projeto de Aprendizagem, mediadas pelas TIC, podemos promover e evidenciar processos metacognitivos em sujeitos participantes de ADA/AVA. As ferramentas dos AVA/ADA proporcionam aos professores um meio de evidenciar os caminhos trilhados pelo aluno das suas verdadeiras aprendizagens. 
Os dados mostram que é relevância da escolha da estratégia de ensino e aprendizagem para promover o processo metacognitivo, pois essas estratégias provocaram os alunos a verbalizar as suas dificuldades, avaliar os percursos realizados e explicar as razões das dificuldades ou sucessos. Permitiram os alunos a conhecer o seu ato de aprender. A estratégia Projeto de Aprendizagem ter sido globalizadora de todo o desenvolvimento da pesquisa contribuiu com os resultados positivos, ou seja, a contextualização e globalização das atividades deu condições aos alunos de refletir sobre seus atos e formas de aprender. A autonomia dada aos alunos permitiu que transparecessem seus pensamentos metacognitivos. A estratégia Mapas Conceituais evidenciou como os sujeitos dessa pesquisa organizam seus pensamentos.

Conclui-se também que para entender as ações humanas e seus motivos, é preciso invocar perspectivas múltiplas e examinar as tensões dialéticas que existem entre elas. Fazer a análise de um processo introspectivo, sem levar em consideração o cenário, propósito, agente e agência pode não validar o dado do fenômeno pesquisado. $\mathrm{O}$ propósito de uma ação, tanto na posição de agente mediador como aluno, está diretamente ligado à capacidade metacognitiva. As ações mediadas, de acordo com as estratégias de ensino e de aprendizagem, permitem a construção partilhada de instrumentos e de processos de significação na construção das operações abstratas do pensamento, dando origem ao processo de internalização, assim como o processo metacognitivo, ou seja, todos os dados coletados nessa pesquisa confirmaram que o processo de desenvolvimento do sujeito acontece, como previsto por Vygotsky (1998) e Sanjurjo (2002), numa espiral ascendente, iniciando no processo interpessoal (interação social) passando para o intrapessoal, de forma não linear, pois ficaram evidenciados avanços e recuos até a própria autorregulação.

O estudo também evidenciou que a falta de subcategorias para autorregulação. Em vários momentos das análises dos dados percebia-se a autorregulação dos casos estudados, porém nem sempre essa capacidade se apresentava com todas as suas características definidas no referencial teórico, uma vez que confirmou-se que a categoria autorregulação está, de fato, ligada a metacognição, uma vez que é definida como a capacidade que o sujeito tem de internalizar o próprio tutor, de planejar e definir objetivos próprios e organizá-los de forma que possa adaptá-los de acordo com o contexto.

\section{Referências}

BOUCHARD-BOUFFARD, T. et al. Self-Regulation on a concept-formation task among average and gifted students. Journal of Experimental Child Psychology, 561993. p. 115-134

BROWN, A. L., CAMPIONE, J. C., DAY, J. D.. Learning to learn: on training students to learn from the texts. Educational Researcher, 10, 1981. p.14-21.

COUCEIRO Figueira, A. P. Metacognição e seus contornos. Revista Iberoamericana de Educación, 2003.

DIAZ, R.; NEAL, C.; AMAYA-WILLIAMS, M. Orígenes sociales de la autorregulación. In: MOLL, L.C (comp) Vygotsky y la educación: connotaciones y aplicaciones de La psicología socio histórica en la educación. Bs. As.: Aique Grupo Editor, 1993.

FINO, Carlos Nogueira. Vygostky e Zona de Desenvolvimento Proximal (ZDP): Três Implicações Pedagógicas. Revista Portuguesa de Educação, v. 14 n.2. Universidade do Minho. Braga, Portugal. 2001.

MATEOS, M. Metacognición y educación, Aique, Buenos Aires. 2001.

NOEL, B. (s.d.). La metacognition. De Boeck Université, Editions Université, Pedagogies en Developpement Problematiques.

PASSERINO, Liliana. Pessoas com Autismo em Ambientes Digitais de Aprendizagem: estudo dos processos de Interação Social e Mediação. Porto Alegre: UFRGS, 2005. Tese 
(Doutorado em Informática na Educação), Programa de Pós-Graduação em Informática na Educação, Universidade Federal do Rio Grande do Sul, 2005.

PASSERINO, Liliana Maria. Uso de ferramentas síncronas para análise da interação social em sujeitos com autismo: um estudo de caso. In: RENOTE : revista novas tecnologias na educação [recurso eletrônico]. Porto Alegre, v. 3, n. 1 maio, 2005.

PERRAUDEAU, Michel. Estratégias de aprendizagem. Como acompanhar os alunos na aquisição dos saberes. Porto Alegre, Artmed. 2009.

PETRUCCI, Valéria Bezzera Cavalcanti; BATISTON, Renato Reis. Estratégias de ensino e avaliação de aprendizagem em contabilidade. In: PELEIAS, Ivam Ricardo. (Org.) Didática do ensino da contabilidade. São Paulo, Saraiva, 2006.

SANJURJO, Liliana O. La formación práctica de los docentes: reflexión y acción en el aula. Santa Fé, Argentina, Homo Sapiens, 2002.

Rede, Informática na Educação: Teoria \& Prática v.3 n.1, Setembro, 2000. Disponível em http://penta2.ufrgs.br/pgie/revista/artigo\%2020arvle.doc

TOASSA, Gisele. Conceito de consciência em Vigotski. Psicol. USP [online]. vol. 17, no. 2, 2006. p. 59-83. Disponível em http://penta2.ufrgs.br/pgie/revista/artigo\%2020arvle.doc

TOMASEllo, M. Orígenes Culturais da Aquisição do Conhecimento Humano. São Paulo, Martins Fontes, (Coleção Tópicos), 2003.

VYGOSTKY L. S. Mind in Society: The Development of Higher Psychological Processes. Cambridge MA, Hardward University Press. 1978.

VYGOTSKY, L. S. A Construção do Pensamento e da Linguagem (texto integral traduzido do russo). São Paulo, Martins Fontes, 2001.

VYGOTSKY, L. S. Formação Social da Mente. 6. ed. São Paulo, Martins Fontes, 1998.

VYGOTSKY, L.S. Pensamento e linguagem. São Paulo, Martins Fontes. 1996.

VYGOTSKY, L.S.; LURIA A.N.. Studies on the History of Behavior- Ape, Primitive, and Child. Hillsdale NJ, Lawrence Erlbaum Associates, 1993.

VYGOTSKY, L.S.;.LURIA A.R; LEONTIEV, A.N. (1933). Aprendizagem e desenvolvimento Intelectual na Idade Escolar. In: Linguagem, desenvolvimento e aprendizagem. São Paulo, Ícone, 1992.

WERSTCH, James. Vygotsky y la formación social de la mente. Serie Cognición y desarrollo humano. Barcelona, Ed. Paidós, 1988.

WERTSCH, J.; A. L. B. SMOLKA. Continuando o diálogo: Vygotsky, Bakthin e Lotman. In: H. Daniels (org.). Vygotsky em foco: pressupostos e desdobramentos. Campinas, Papirus Editora, 1993.

WERTSCH, J. La voz de la racionalidad en un enfoque sociocultural de la mente.In: MOLL, L.C (comp.) Vygotsky y la educación: connotaciones y aplicaciones de la psicología socio histórica en la educación. Bs. As: Aique Grupo Editor, 1993.

WERTSCH, James V.; DEL RIO, Pablo; ALVAREZ, Amélia. Prefácio: Estudos Socioculturais: História, Acão e Mediação. In: WERTSCH, James V.; DEL RIO, Pablo ALVAREZ. Estudos Socioculturais da Mente. Porto Alegre, Artmed, 1998.

WERTSCH,J. La Mente en Acción. Buenos Aires, Aique, 1999.

YIN, R. K. Estudo de Caso: Planejamento e Métodos. $4^{\text {a }}$ ed. Porto Alegre, Bookman, 2010.

ZABALA, Antoni. Enfoque globalizador e pensamento complexo. Uma proposta para o currículo escolar. Porto Alegre, Artmed, 2002. 